contacts we should therefore concentrate on the adolescent group. I have already (1936) pointed out how inadvisable it was to appear to encourage neglect of examination of child contacts. It has since occurred to me that yet another aspect must be considered in this "worthwhile" argument $\rightarrow$ the relative number of contacts at various ages.

The following investigation is not considered extensive enough for forming definite conclusions, but it does serve as a pointer, and its publication may encourage a similar investigation on a larger scale.

\section{The Investigation}

All the patients in the wards of the County Sanatorium, Clare Hall, were interviewed, and information was obtained on the number and ages of the persons in contact with them before admission to the sanatorium. Particular care was taken to ascertain the actual contacts in the home, and neither the family nor the house were taken as the unit. This care is necessary because of lodgers and sublet rooms, and in regard to patients living "on their own." The results are shown in Tables I to III ; they were worked out separately for the men and the women patients so that there might be a slight check on the error of sampling.

TABle I.-Female Patients

69 patients -211 contacts -3.0 contacts per patient. The contacts were distributed as follows:

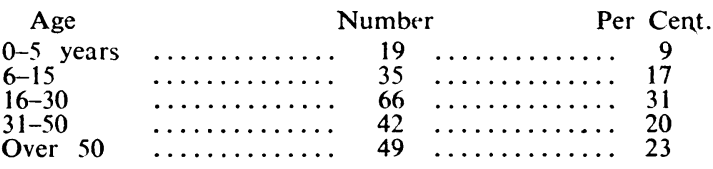

TABLE II.-Male Patients

119 patients -377 contacts -3.1 contacts per patient The contacts were distributed as follows:

\begin{tabular}{|c|c|c|c|}
\hline Age & Numbe & & er Cent. \\
\hline $0-5$ years & . 30 & .. & 8 \\
\hline & …........ & n.......... & 20 \\
\hline $16-30$ & $\ldots \ldots \ldots \ldots \ldots, 13 i$ & $\ldots \ldots \ldots \ldots \ldots$ & 35 \\
\hline $31-50$ & $\ldots \ldots \ldots \ldots \ldots$ & & 19 \\
\hline Over 50 & $\ldots \ldots$ & $\ldots \ldots \ldots$ & 19 \\
\hline
\end{tabular}

188 patients -588 contacts -3.1 contacts per patient. The contacts were distributed as follows:

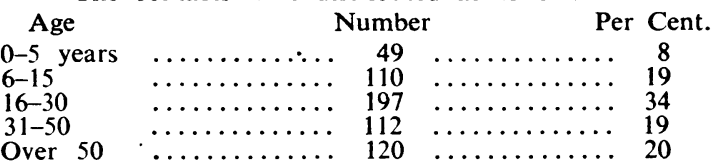

\section{Comment}

There is a close similarity in the figures obtained from the male and the female patients. The figure of three contacts to a tuberculous patient is interesting as showing that the index of 2.5 may be too low in regard to families containing a tuberculous adult. It should be remembered, however, that in this investigation the home and not the family was the unit, as it should be in dealing with contacts; and another point to be noted is that at Clare Hall children under 15 were not admitted.

From the figures in the tables I should like to comment on two age groups. A fifth of the contacts are over 50. At first sight the detection of tuberculous disease in these might appear relatively unimportant. This, however, is not so. For it is in just this group that the primary case might be found-that is, the person responsible for the disease in the patient whose contacts are being examined. And the discovery of the primary case is vital, as otherwise the removal of the tuberculous patient from the home will lead to a fool's paradise in regard to the other inmates.

The low percentage of contacts under the age of 6 is of interest in regard to the argument at the beginning of this note. Tuberculosis is a relatively mild disease in children over the age of 5 . Moreover, the form it usually assumes in them (affecting bones, joints, and glands) leads to advice being sought by parents spontaneously. There is, too, the fact that children over 5 come under the supervision of the school medical service. None of these circumstances applies to very young children. In them detection of tuberculous disease or infection and the prevention of infection is of paramount importance (Kayne, 1935, 1936). The relatively small percentage ( 8 per cent.) of these children in the whole group of contacts would therefore hardly justify a policy that encourages less concentration on the examination of young children on the ground of the alleged large total number of contacts to be examined.

I have to thank Dr. F. A. H. Simmonds, medical superintendent, for permission to carry out the investigation, and Dr. John Tate, county medical officer, Middlesex County Council, for permission to publish this note.

\section{REFERENCES}

Transactions of the Twenty-second Annual Conference of the National Association for the Prevention of Tuberculosis, 1936. Kayne, G. G. (1935). Proc. roy. Soc. Med., 28.60. (1936). Lancet, 2, 286.

\section{SEVERE RECTAL INJURIES CAUSED BY AN ENEMA GIVEN THROUGH A RIGID NOZZLE}

\author{
BY
}

\section{WALTER W. GALBRAITH, M.B., Ch.B., F.R.F.P.S.Glas. \\ Visiting Surgeon, Western Infirmary, Glasgow}

Injuries to the rectum following on the administration of a soap-and-water enema are not common, but when they do occur they may be of so serious a nature that I consider the following case should be put on record.

\section{C:inical Record}

A married woman, age 56, of somewhat stout build, had suffered for many years from chronic bronchitis and asthma. On March 5, 1932, she was seized with a severe rigor during the night. She felt increasingly ill during the next two days, when her doctor (Dr. W. D. Allan) was called in. He found her to be suffering from bronchopneumonia affecting one lung. Two days later both lungs were involved, and she was critically ill. In ten days' time she had improved somewhat, but was still very ill. At this time the patient was given an enema by her daughter. An ordinary Higginson's syringe with a bone nozzle, as usually supplied by chemists, was used. The result of the enema was said to be poor. The patient complained of no pain at the time the enema was given, apart from a little rectal discomfort. Following the enema she had retention of urine, which was relieved by catheterization, and two days later she complained of pain in the rectum. Pyrexia, which was attributed to the chest condition, continued. The pain in the rectum was regarded as being due to piles, there being no external evidences of any other cause. Eight days later catheterization was still necessary, and at that time the rectal pain, which had been relieved by a sedative ointment, became more severe. Faecal matter was noticed issuing from the vagina, and there was also incontinence of 
faeces. The chest condition improved, but the temperature remained elevated $\left(100^{\circ}\right)$. When her doctor noticed the faecal vaginal discharge (ten days after the enema) he made a rectal examination, and was horrified to find no trace of the rectum, but instead his finger went into a huge cavity, limited behind by the coccyx and sacrum and in front by the posterior vaginal wall, in the distal part of which there was an opening of a size sufficient to admit the index finger. Dr. Allan asked me to see her in consultation that evening. The patient stated that she had had no rectal pain until a day or two after the administration of the enema. When questioned closely she admitted that the enema caused a slight pain, which she attributed to piles, from which she habitually suffered. As the pain did not persist she did not worry about it. She stated that for years she was accustomed to give herself enemata, as she preferred this to the use of purgatives. Her general condition was poor, and I considered that her best chance was to be nursed at home under the care of her own doctor until her chest condition improved sufficiently to warrant her removal to hospital.

On April 16, 1932, the patient was admitted to the David Elder Infirmary (annexe of the Western Infirmary) under my care. On her admission to the Infirmary it was noted that there was still considerable bronchitis and some embarrassment of respiration. She had retention of urine and a continuous oozing of foul-smelling faecal and purulent material from the vagina. Rectal and vaginal examination revealed an almost complete loss of the recto-vaginal septum and an absence of the posterior wall of the rectum. The examining finger came in close contact with the coccyx and the foramina in the lower part of the sacrum. Temperature, $98.8^{\circ}$; pulse, 92 ; respirations, 22. On April 22, 1932, a colostomy was performed. During the operation the lower peritoneal cavity was explored, but no abnormality was noted. The colostomy was opened two days later. Following the colostomy the patient made an uninterrupted recovery. The retention of urine was relieved within a day or two, and in fourteen days the recto-vaginal fistula had healed. The cavity behind the rectum discharged pus for several weeks, but ultimately it closed. The patient was discharged from the Infirmary on June 28, 1932, when it was noted that within the anus there was only a narrow track, which was lined by granulation tissue and which would not admit a finger.

The patient has reported from time to time, and when last seen a few weeks ago she appeared to be in good general health. She had no asthma or bronchitis, and the chest appeared healthy. There was still a small amount of discharge issuing from the anus, into which a finger could not be inserted. A sinus evidently existed between the end of the pelvic colon and the anus. She had good control of the colostomy wound, which functioned twice daily.

\section{Other Cases}

I was called in consultation to see this patient within a few weeks of reading an article by $\mathbf{H}$. $\mathbf{H}$. Rayner (British Medical Journal, 1932, 1, 419), in which he described a case in many ways similar, but in which the injury was of less extent. I had meant to put this case on record at the time but thought that I should observe the patient for a year or two with a view to ascertaining the final condition following on the injury. At a meeting of the North of England Obstetrical and Gynaecological Society on December 17, 1929, W. W. King (Sheffield) reported a case, and subsequently, in the discussion which followed, four similar cases were mentioned by others (British Medical Journal, 1930, 1, 113). These communications all referred to injuries caused by enemata immediately before or after labour. Denham Pinnock (Lancet, 1937, 1, 205) refers to two cases similar to the one above described, but in his cases the injury was not so extensive or the history so peculiar.
The rigid douche or enema nozzle can hold such potential dangers that its use should never be permitted under any circumstances, and more especially in the hands of the patient, his friends, or even a nurse.

I desire to express indebtedness to Dr. W. D. Allan for his notes about the patient both before her admission and since her discharge from hospital.

\section{Clinical Memoranda}

\section{Carcinoma of Rectum in a Youth of 18}

The following case seems worthy of record by reason of the patient's age:

A youth aged 18 years consulted me in the late summer complaining of diarrhoea of sudden onset; there was no previous history of diarrhoea and a kaolin mixture was given. There was some improvement, and the medicine was repeated five days later. He was seen again nine days afterwards, the diarrhoea having recurred after transient improvement. The rectum was examined and a hard mass was felt three and a half inches from the anus, the tip of the finger slipping over the hard edge into a deep ulcer crater.

Laparotomy was performed that day. The liver was found to be free from secondary growths, but there was a hard mass the size of a walnut in the pelvic mesocolon one inch below the sacral promontory. There was a suspicion of a dimpling of the peritoneum covering the left side of this small mass. A left inguinal colostomy was performed, and the colon was opened on the third day. Ten days later under spinal anaesthesia an abdomino-perineal excision of the rectum was performed (Miles's technique). When the abdomen was opened the bladder was found to be full, in spite of the fact that the patient had passed water before coming to the theatre. Difficulty was experienced in catheterizing him because the growth was deforming the base of the bladder, which organ was pulled downwards and forwards in that region, presumably by contraction of surrounding tissues. The bladder was emptied by a silver catheter. ' The operation was completed by lining the large subperitoneal cavity with oiled silk and plugging with vaseline gauze, which was renewed on the fifth day and discontinued on the eighth day.

He was allowed home on the tenth day, the large cavity being irrigated daily with a pint of cold eusol. Walking was allowed on the twenty-third day; the perineum was completely healed eight weeks after operation; he was certified fit for work twelve weeks after operation.

Massive doses of iron ( 3 ii of ferri et ammon. cit. daily) were given and it was found that, not only did the patient gain strength rapidly, but the management of the colostomy was thereby facilitated in that the stools were well formed and had very little odour. All that was necessary was to cut a hole the size of the spur in a piece of lint which was laid on the abdomen; a vaselined piece of lint was laid on the spur. When he was dressed the formed stool had been deposited on the lint and the whole was removed and burnt forthwith. Very seldom was the skin of the abdominal wall soiled. The skin was kept in perfect condition by a zinc, boric, and french chalk dusting powder.

The pathologist's report proved the growth to be an adenocarcinoma. The hard mass in the pelvic mesocolon proved to be a lymphatic gland invaded by growth.

\section{CONCLUSIONS}

1. Before operation for excision of the rectum the bladder should be emptied by catheter.

2. During the nursing period the colostomy is best managed by giving large doses of the scale preparation of iron.

Longtown, Cumberland.

R. RUTHERFORD. 